\title{
Creation of a rectal cancer registry in Italy by the Advanced \\ International Mini-Invasive Surgery (AIMS) academy clinical
}

\section{research network [version 1; peer review: 3 approved]}

\author{
Giulio M. Mari (D1), Pietro Achilli (D2, Dario Maggioni' ${ }^{1}$, Jacopo Crippa2,
} Andrea T.M. Costanzi ${ }^{1}$, Mauro A. Scotti ${ }^{3}$, Vittorio Giardini ${ }^{3}$, Mattia Garancini ${ }^{3}$, Eugenio Cocozza4, Giacomo Borroni ${ }^{4}$, Ilaria Benzoni ${ }^{5}$, Mario Martinotti5, Luigi Totaro5, Matteo Origi6, Michele Mazzola6, Giovanni Ferrari6, Antonio Ziccarelli ${ }^{7}$, Roberto Petri7, Vincenzo Bagnardi8, Giacomo Pugliese9, Antonello Forgione ${ }^{6}$, Raffaele Pugliese ${ }^{9}$, AIMS Academy Clinical Research Network

\author{
${ }^{1}$ General Surgery Department, Desio Hospital, Desio, Italy \\ ${ }^{2}$ General Surgery Residency Program, University of Milan, Milan, Italy \\ ${ }^{3}$ General Surgery Department, San Gerardo Hospital, Monza, Italy \\ ${ }^{4}$ General Surgery Department, Varese Hospital, Varese, Italy \\ ${ }^{5}$ Department of Surgery, Cremona Hospital, Cremona, Italy \\ ${ }^{6}$ General Surgery Department, Niguarda Hospital, Milan, Italy \\ ${ }^{7}$ General Surgery Department, AOU "SSMM della Misericordia", Udine, Italy \\ ${ }^{8}$ Department of Statistics and Quantitative Methods, University of Milan-Bicocca, Milan, Italy \\ ${ }^{9}$ AIMS Academy Clinical Research Network, Advanced International Mini-Invasive Surgery (AIMS) Academy, Milan, Italy
}

\section{V1 First published: 10 Oct 2019, 8:1736 \\ https://doi.org/10.12688/f1000research.20702.1 \\ Latest published: 10 Oct 2019, 8:1736 \\ https://doi.org/10.12688/f1000research.20702.1}

\section{Abstract}

Background: The management of rectal cancer is multimodal and involves a multidisciplinary team of cancer specialists with expertise in medical oncology, surgical oncology, radiation oncology and radiology. It is crucial for highly specialized centers to collaborate via networks that aim to maintain uniformity in every aspect of treatment and rigorously gather patients' data, from the first clinical evaluation to the last follow-up visit.

The Advanced International Mini-Invasive Surgery (AIMS) academy clinical research network aims to create a rectal cancer registry. This will prospectively collect the data of patients operated on for nonmetastatic rectal cancer in high volume colorectal surgical units through a well design pre-fashioned database for non-metastatic rectal cancer, in order to take all multidisciplinary aspects into consideration.

Methods/Design: The protocol describes a multicenter prospective observational cohort study, investigating demographics, frailty,

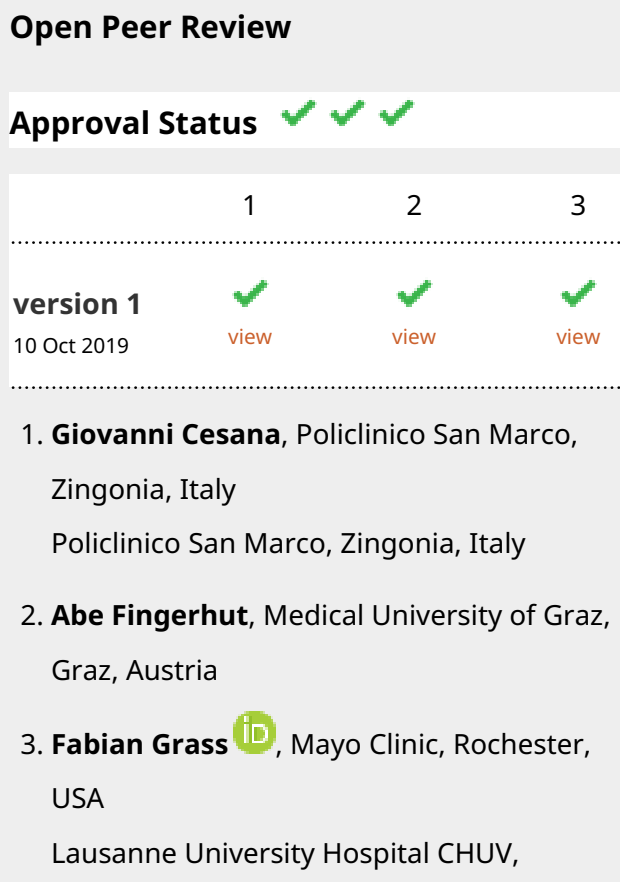

1. Giovanni Cesana, Policlinico San Marco,

Zingonia, Italy

Policlinico San Marco, Zingonia, Italy

2. Abe Fingerhut, Medical University of Graz, Graz, Austria

3. Fabian Grass (ID), Mayo Clinic, Rochester, USA

Lausanne University Hospital CHUV, 
cancer-related features, surgical and radiological parameters, and oncological outcomes among patients with non-metastatic rectal cancer who are candidates for surgery with curative intent. Patients enrolled in the present registry will be followed up for 5 years after surgery.

Discussion: Standardization and centralization of data collection for neoplastic diseases is a virtuous process for patient care. The creation of a register will allow the control of the quality of treatments provided and permit prospective and retrospective studies to be carried out on complete and reliable high quality data. Establishing data collection in a prospective and systematic fashion is the only possibility to preserve the enormous resource that each patient represents.

\section{Keywords}

Rectal surgery, registry, network

\section{Lausanne, Switzerland}

Any reports and responses or comments on the article can be found at the end of the article.

Corresponding author: Giulio M. Mari (giul_mari@yahoo.it)

Author roles: Mari GM: Conceptualization; Achilli P: Writing - Original Draft Preparation; Maggioni D: Investigation; Crippa J: Writing Review \& Editing; Costanzi ATM: Data Curation; Scotti MA: Investigation; Giardini V: Investigation; Garancini M: Investigation; Cocozza E: Methodology; Borroni G: Methodology; Benzoni I: Project Administration; Martinotti M: Supervision; Totaro L: Project Administration; Origi M: Investigation; Mazzola M: Investigation; Ferrari G: Supervision; Ziccarelli A: Investigation; Petri R: Investigation; Bagnardi V: Data Curation, Formal Analysis, Methodology; Pugliese G: Software; Forgione A: Methodology; Pugliese R: Supervision;

Competing interests: No competing interests were disclosed.

Grant information: The author(s) declared that no grants were involved in supporting this work.

Copyright: ( $) 2019$ Mari GM et al. This is an open access article distributed under the terms of the Creative Commons Attribution License , which permits unrestricted use, distribution, and reproduction in any medium, provided the original work is properly cited.

How to cite this article: Mari GM, Achilli P, Maggioni D et al. Creation of a rectal cancer registry in Italy by the Advanced International Mini-Invasive Surgery (AIMS) academy clinical research network [version 1; peer review: 3 approved] F1000Research 2019, 8:1736 https://doi.org/10.12688/f1000research.20702.1

First published: 10 Oct 2019, 8:1736 https://doi.org/10.12688/f1000research.20702.1 


\section{Introduction}

There are nearly 125,000 new cases of rectal cancer diagnosed every year in Europe, representing one of the leading causes of cancer-related morbidity and mortality world-wide ${ }^{1}$. Five decades ago, the prognosis of rectal cancer was poor, with locoregional cancer recurrence rates of up to $40 \%$ and 5-year survival rates of $<50 \%$ for locally-advanced tumors ${ }^{2}$. These disappointing outcomes were improved by innovations in surgical technique, multimodality therapy and education ${ }^{3}$.

Total mesorectal excision (TME) remains the cornerstone in the treatment of non-metastatic rectal cancer. To achieve high quality TME, which is the key-factor for proper oncological resection, surgeons must respect well-known embryological planes, which were made famous as the boundaries of Heald's Holy plane ${ }^{4}$.

While the surgical principles for rectal cancer have changed little during the last decade, the novelties in the radiological study of the disease, as well as in the administration of neoadjuvant and adjuvant therapy, have largely modified the treatment of this neoplasm ${ }^{5}$. Nowadays, the management of rectal cancer is multimodal and involves a multidisciplinary team of cancer specialists with expertise in medical oncology, surgical oncology, radiation oncology and radiology. Therefore, it is becoming crucial for highly specialized centers to design prefashioned databases for non-metastatic rectal cancer in order to take all multidisciplinary aspects into consideration. Previous attempts to establish rectal cancer registries, such as The Norwegian Rectal Cancer Project ${ }^{6}$ and The Spanish Rectal Cancer Project ${ }^{7}$, were based on the need to first extend adequate oncological treatment, and second to increase the use of minimally invasive surgery.

The Advanced International Mini-Invasive Surgery (AIMS) academy clinical research network aims to create a rectal cancer registry that will prospectively collect data of patients operated on for non-metastatic rectal cancer in high volume colorectal surgical units, maintaining uniformity in every aspect of the treatment and rigorously gathering patients data, from the first clinical evaluation to the last follow-up visit.

\section{Purpose}

The aim of the AIMS academy clinical research network rectal cancer registry is to prospectively collect data from different minimally-invasive colorectal units in Northern Italy, with standardization of the pre-operative, intra-operative and postoperative management for patients operated on for non-metastatic rectal cancer with curative intent.

The primary outcome is to prospectively collect short and long term oncological outcomes. The second outcome is to collect information on the compliance of patients to oncological treatments, both in neoadjuvant and adjuvant settings and their quality of life.

\section{Protocol}

Study design

This protocol describes a multicenter prospective observational cohort study, investigating demographics, cancer-related features and oncological outcomes among patients who are nonmetastatic rectal cancer candidates for surgery with curative intent. Patients enrolled in the present registry will be followed up for 5 years after surgery. All participating centres are public tertiary non-academic hospitals of northern Italy.

The study was approved by the Comitato Etico Scientifico Milano Area 3 (protocol number 295-052019). The study protocol has been registered as an observational study at ClinicalTrials.gov: NCT04045236 (first received, 3 August 2019). All participating centres received approval from local ethics committees.

\section{Patients and eligibility criteria}

Patients receiving the diagnosis of non-metastatic rectal cancer and the indication for a curative treatment will be enrolled in the registry. The target population will consist of all patients enrolled in the participating centers from the start of the rectal cancer registry on. Patients will be identified through their medical record numbers. One investigator in each center will obtain written informed consent from each patient and keep the patients updated on data collection.

Inclusion criteria: 1) histologically proved adenocarcinoma of the rectum; 2) patient aged $>18$ years old; 3) indication for surgical resection with curative intent.

Exclusion criteria: need for emergency surgery, palliative operation or metastatic disease at presentation.

\section{Data collection}

Demographic information and anamnesis with a focus on oncologic history will be recorded at the first outpatient visit, together with a complete clinical examination. Data regarding the symptoms of presentation will be collected and categorized as haemorrhagic framework, alteration of bowel habits or pain. Every patient will undergo a pre-operative staging (see Extended data: CRF1) with chest-abdominal computerized tomography scan with intravenous contrast, complete colonoscopy, pelvic magnetic resonance (MR) imaging and endorectal ultra sound (EUS) examination. Blood sample with serum level of CEA, CA 19.9 and a full nutritional panel will be collected and analysed. Charlson Comorbidities Index adjusted for age $^{8}$ will be calculated for every patient, while those $>70$ years old will be assessed for frailty risk using the modified Frailty Index (mFI) described by Robinson et al. ${ }^{9}$ (see Extended data: CRF1).

All data regarding radiation doses received, total amount of chemotherapy administered and number of cycles, toxicities or adverse reaction and possible reasons for not completed treatment 
schedule will be collected for all the patients with locally advance rectal cancer, who received neo adjuvant chemoradiotherapy. Radiological restaging after neoadjuvant treatment comprises MR imaging, EUS and colonoscopy. Radiological response to neoadjuvant treatment will be measured following a uniform score system among all centers involved ${ }^{10}$. Endoscopic assessment of tumour regression will be also recorded ${ }^{11}$ (see Extended data: $\mathrm{CRF} 2)$.

Intraoperative analysed parameters will be included in the registry (see Extended data: CRF3), with special attention to technical aspects of surgical procedures, such as level of inferior mesenteric artery ligation, type of energy device used, number and type of cartridge, and size of circular stapler and all other variables detailed in the Clinical Trials registration.

Histopathological examination will be performed according to WHO 2010 guidelines $^{12}$. Macroscopic evaluation of the resected specimen will be classified according to the Quirke score $^{13}$, while pathologic regression grade will be estimated according to a five-point scoring system ${ }^{14}$. Mismatch repair status will be reported when analysed (see Extended data: CRF3).

Post-operative complications will be reported according to the Clavien-Dindo scale ${ }^{15}$. Length of stay and eventual postdischarge complications will be evaluated and recorded. Application of an ERAS protocol will be considered only for at least $80 \%$ of ERAS colorectal items satisfied (see Extended data: CRF4) ${ }^{16}$.

Indication to adjuvant treatment will be defined within a multidisciplinary setting. Regarding adjuvant chemotherapy, all data of interest such as number of cycles, toxicities and possible early interruption of the treatment will be collected as previously shown in the neoadjuvant setting. Oncological followup will be performed according to National Comprehensive Cancer Network guidelines ${ }^{17}$. One investigator in each center will carry out the follow up. Functional follow up will be done yearly according to the Low Anterior Resection Syndrome Score (see Extended data: CRF5) ${ }^{18}$.

\section{Data management}

Data will be collected daily using a pre-fashioned REDCAP database by one physician for each hospital and referred to a research fellow (GMM) who will monitor the included data for all institutions. Pre-fashioned CRFs are available as Extended data. There will be regular contact between the study coordinators and the participating centers through scheduled meetings every three months. A data manager (GP) will regularly control the quality of the data provided.

\section{Dissemination of the registry}

All researchers will be able to access the data uploaded. Data will be hosted by the AIMS Academy. All researchers will be able to use collected data to write scientific articles or to plan surgical audits.

\section{Study status}

The registry has been enrolling patients since January 2019.

\section{Discussion}

The primary aim of this registry is to prospectively collect data from different minimally invasive colorectal units in Northern Italy with a standardization of the pre-operative, intra-operative and post-operative management for patients operated on for nonmetastatic rectal cancer with curative intent.

Standardization and centralization of data collection for neoplastic diseases is a virtuous process for patient care. The creation of a register allows the control of the quality of treatments provided and permits prospective and retrospective studies to be carried out on complete and reliable high quality data.

In the last few years, the need to raise the quality of care for rectal cancer patients has been reported in numerous studies ${ }^{19}$, as well as the clear association between hospital volumes and outcomes after rectal surgery ${ }^{20}$. Speaking a common language in such a complex field is no longer a benefit but rather the only way to face new challenges waiting for us in the near future.

Due to the aging population, the number of frail patients affected by rectal cancer is expected to grow $^{21}$. As a consequence, the identification of frail patients and the need to search for tailored management able to prevent adverse complications and to improve clinical outcomes of this population will play a fundamental role in oncological surgery in the years to come ${ }^{22}$. Thus, all methods available to screen a patient for frailty, such as the Mini Cog test, the Katz Index of Independence in Activities of Daily Living (ADL), and the Timed Up and Go (TUG) test must become an integrated part of daily clinical work ${ }^{23,24}$.

The accuracy achieved by pre-operative MR imaging during the last decade ${ }^{25}$ has lead to important results in both preoperative staging and radiologic response evaluation after neo-adjuvant therapy $^{26}$. Indeed, radiologic restaging is increasingly involved in the therapeutic decision-making process ${ }^{27}$. Thus, structuring a synoptic and uniform MR report must become a prerogative in management of rectal cancer patients.

As mentioned in the study protocol section, intra-operative data concerning which type of devices or staplers used during surgery will be recorded in the registry, allowing us to look for possible correlations with clinical outcomes. A wellstructured prospective analysis among high volume units will help to define the real complication rate after rectal cancer surgery, which has been usually derived retrospectively and therefore potentially underestimated ${ }^{28}$.

Regarding surgical expertise among the centers involved, continuous monitoring of the integrity of the resected specimens should definitely increase the overall quality of surgery.

Detailed analysis of the compliance to adjuvant chemotherapy for locally advanced rectal cancer is extremely important considering recent data reported in the literature ${ }^{29,30}$. The unexpected low level of compliance reported in these previous case series has questioned the traditional administration of 
adjuvant chemotherapy, searching for new strategies for locally advanced rectal tumours, such as total neoadjuvant chemotherapy ${ }^{3}$.

\section{Conclusions}

The creation of a registry for patients operated on for nonmetastatic rectal cancer is a necessary requirement. Establishing data collection in a prospective and systematic fashion is the only possibility to preserve the enormous resource that each patient represents.

\section{Data availability}

Underlying data

No underlying data is associated with this article.

\section{Extended data}

Zenodo: Rectal cancer AIMS Academy clinical research network registry, http://doi.org/10.5281/zenodo.346362731
This project contains the following extended data:

- CRF1: Patient's information and cancer staging form.

- CRF2: Neo-adjuvant chemoradiotheraphy and cancer restaging form.

- CRF3: Surgery, surgical outcomes and pathological examination form.

- CRF4: Adjuvant chemotherapy form.

- CRF5: Oncological follow-up form.

Data are available under the terms of the Creative Commons Zero "No rights reserved" data waiver (CCO 1.0 Public domain dedication).

Acknowledgements

AIMS Academy: www.aimsacademy.org
1. European cancer information system: Estimates of cancer incedence and mortality in 2018, for all countries. European commission. Reference Source

2. Slaney G: Results of treatment of carcinoma of the colon and rectum. Mod Trends Surg. 1971; 3: 69-89. PubMed Abstract

3. Zaborowski A, Stakelum A, Winter DC: Systematic review of outcomes after total neoadjuvant therapy for locally advanced rectal cancer. Br J Surg. 2019; 106(8): 979-987.

PubMed Abstract | Publisher Full Text

4. Heald RJ, Moran BJ, Ryall RD, et al.: Rectal cancer: The Basingstoke experience of total mesorectal excision, 1978-1997. Arch Surg. 1998; 133(8): 894-9. PubMed Abstract | Publisher Full Text

5. Al-Sukhni E, Milot L, Fruitman M, et al.: Diagnostic accuracy of MRI for assessment of T category, lymph node metastases, and circumferential resection margin involvement in patients with rectal cancer: a systematic review and meta-analysis. Ann Surg Oncol. 2012; 19(7): 2212-23. PubMed Abstract | Publisher Full Text

6. Wibe A, Møller B, Norstein J, et al:: A national strategic change in treatment policy for rectal cancer--implementation of total mesorectal excision as routine treatment in Norway. A national audit. Dis Colon Rectum. 2002; 45(7): 857-66.

PubMed Abstract | Publisher Full Text

7. Ortiz H, Ciga MA, Armendariz P, et al:: Multicentre propensity score-matched analysis of conventional versus extended abdominoperineal excision for low rectal cancer. Br J Surg. 2014; 101(7): 874-882. PubMed Abstract | Publisher Full Text

8. Charlson M, Pompei P, Ales KL, et al:: A new method of classifying prognostic comorbidity in longitudinal studies: development and validation. $J$ Chronic Dis. 1987; 40(5): 373-383.

PubMed Abstract | Publisher Full Text

9. Robinson TN, Wu DS, Pointer L, et al.: Simple frailty score predicts postoperative complications across surgical specialties. Am J Surg. 2013; 206(4): 544-550.

PubMed Abstract | Publisher Full Text | Free Full Text

10. Beets-Tan RGH, Lambregts DMJ, Maas M, et al:: Correction to: Magnetic resonance imaging for clinical management of rectal cancer: Updated recommendations from the 2016 European Society of Gastrointestinal and Abdominal Radiology (ESGAR) consensus meeting. Eur Radiol. 2018; 28(6): 2711. PubMed Abstract | Publisher Full Text

11. Sohn DK, Han KS, Kim BC, et al.: Endoscopic assessment of tumor regression after preoperative chemoradiotherapy as a prognostic marker in locally advanced rectal cancer. Surg Oncol. 2017; 26(4): 453-459. PubMed Abstract | Publisher Full Text

12. Ft B, F C, Rh $\mathrm{H}$, et al:: WHO classification of tumours of the digestive system. J Clin Ultrasound. 2014

13. Quirke P, Dixon MF, Durdey $\mathrm{P}$, et al.: Local recurrence of rectal adenocarcinoma due to inadequate surgical resection. Histopathological study of latera tumour spread and surgical excision. Lancet. 1986; 2(8514): 996-9. PubMed Abstract | Publisher Full Text

14. Ryan R, Gibbons D, Hyland JMP, et al:: Pathological response following longcourse neoadjuvant chemoradiotherapy for locally advanced rectal cancer. Histopathology. 2005; 47(2): 141-146. PubMed Abstract | Publisher Full Text

15. Dindo D, Demartines N, Clavien PA: Classification of surgical complications: a new proposal with evaluation in a cohort of 6336 patients and results of survey. Ann Surg. 2004; 240(2): 205-213.

PubMed Abstract | Publisher Full Text | Free Full Text

16. Gustafsson UO, Scott MJ, Hubner M, et al:: Guidelines for Perioperative Care in Elective Colorectal Surgery: Enhanced Recovery After Surgery (ERAS ${ }^{\oplus}$ Society Recommendations: 2018. World J Surg. 2019; 43(3): 659-695 Publisher Full Text

17. NCCN guidelines version 4.2018: Colon Cancer. () National Comprehensive Cancer Network, Inc. All Rights Reserved. 2014. Reference Source

18. Emmertsen $\mathrm{KJ}$, Laurberg S: Low anterior resection syndrome score: development and validation of a symptom-based scoring system for bowel dysfunction after low anterior resection for rectal cancer. Ann Surg. 2012; 255(5): 922-928.

PubMed Abstract | Publisher Full Text

19. Merchea A, Ali SM, Kelley SR, et al.: Long-Term Oncologic Outcomes of Minimally Invasive Proctectomy for Rectal Adenocarcinoma. J Gastrointest Surg 2018; 22(8): 1412-1417. PubMed Abstract | Publisher Full Text

20. Hagemans JAW, Alberda WJ, Verstegen M, et al:: Hospital volume and outcome in rectal cancer patients; results of a population-based study in the Netherlands. Eur J Surg Oncol. 2019; 45(4): 613-619. PubMed Abstract | Publisher Full Text

21. Clegg A, Young J, lliffe S, et al.: Frailty in elderly people. Lancet. 2013; 381(9868) 752-762.

PubMed Abstract | Publisher Full Text | Free Full Text

22. Fagard K, Leonard S, Deschodt $\mathrm{M}$, et al.: The impact of frailty on postoperative outcomes in individuals aged 65 and over undergoing elective surgery for colorectal cancer: A systematic review. J Geriatr Oncol. 2016; 7(6): 479-491. PubMed Abstract | Publisher Full Text

23. Ghignone F, Van Leeuwen BL, Montroni I, et al.: The assessment and management of older cancer patients: A SIOG surgical task force survey on surgeons' attitudes. Eur J Surg Oncol. 2016; 42(2): 297-302. PubMed Abstract | Publisher Full Text

24. Montroni I, Rostoft S, Spinelli A, et al.: GOSAFE - Geriatric Oncology Surgica Assessment and Functional rEcovery after Surgery: early analysis on 977 patients. J Geriatr Oncol. 2019; pii: S1879-4068(19)30168-7. PubMed Abstract | Publisher Full Text

25. Kennedy ED, Simunovic M, Jhaveri K, et al:: Safety and Feasibility of Using 
Magnetic Resonance Imaging Criteria to Identify Patients with "good Prognosis" Rectal Cancer Eligible for Primary Surgery: The Phase 2 Nonrandomized QuickSilver Clinical Trial. JAMA Oncol. 2019; 5(7):

961-966.

PubMed Abstract | Publisher Full Text | Free Full Text

26. Siddiqui MRS, Bhoday J, Battersby NJ, et al.: Defining response to radiotherapy in rectal cancer using magnetic resonance imaging and histopathological scales. World J Gastroenterol. 2016; 22(37): 8414-8434.

PubMed Abstract | Publisher Full Text | Free Full Text

27. Bhoday J, Balyasnikova S, Wale A, et al:: How Should Imaging Direct/Orient Management of Rectal Cancer?. Clin Colon Rectal Surg. 2017; 30(5): 297-312. PubMed Abstract | Publisher Full Text | Free Full Text

28. Lin Z, Jiang ZL, Chen DY, et al:: Short- and long-term outcomes of laparoscopic versus open surgery for rectal cancer. Medicine (Baltimore). 2018; 97(50): e13704. PubMed Abstract | Publisher Full Text | Free Full Text

29. Bosset JF, Calais G, Mineur L, et al.: Fluorouracil-based adjuvant chemotherapy after preoperative chemoradiotherapy in rectal cancer: Long-term results of the EORTC 22921 randomised study. Lancet Oncol. 2014; 15(2): 184-9010. PubMed Abstract | Publisher Full Text

30. Mari GM, Maggioni D, Crippa J, et al:: Compliance to Adjuvant Chemotherapy of Patients Who Underwent Surgery for Rectal Cancer: Report from a Multiinstitutional Research Network. World J Surg. 2019; 43(10): 2544-2551. PubMed Abstract | Publisher Full Text

31. Mari G, Achill P: Rectal cancer AIMS Academy clinical research network registry. Zenodo. 2019.

http://www.doi.org/10.5281/zenodo.3463627 


\title{
Open Peer Review
}

\section{Current Peer Review Status:}

\section{Version 1}

Reviewer Report 14 November 2019

https://doi.org/10.5256/f1000research.22769.r55725

(C) 2019 Grass F. This is an open access peer review report distributed under the terms of the Creative Commons Attribution License, which permits unrestricted use, distribution, and reproduction in any medium, provided the original work is properly cited.

\author{
Fabian Grass \\ 1 Department of Colon and Rectal Surgery, Mayo Clinic, Rochester, MN, USA \\ 2 Lausanne University Hospital CHUV, Lausanne, Switzerland
}

The Northern Italian research group presents a study protocol detailing specifics of a rectal cancer registry, which consists of a multicentric collaboration aiming to gather reliable, prospectively collected data for rectal cancer research. The authors need to be congratulated for their initiative. Multi-institutional collaborations are needed in the rapidly evolving field of multi-modal treatment of locally advanced rectal cancer. The authors emphasise new challenges of an ageing, frail population. Radiotherapy- or surgery-sparing strategies may represent interesting alternatives to conventional treatment schemes.

Overall the protocol is clear and concise. I would like to suggest expanding on the following points:

Multi-institutional collaborations are challenging, since dealing with a heterogeous patientand provider population, surgical and perioperative care. How do the authors account for that?

Standardization: Do all centers use similar treatment protocols? How standardized is the surgical approach? Do all centers perform robotic proctoectomy? How experienced are participating surgeons? Are all participating centers teaching facilities?

I think the authors may expand on complication assessment. Who is assessing complications, are these institution-specific abstractors or do centers dispose of surveillance tools, i.e. for surgical site infections?

How do the authors ascertain data quality? National data registries ideally need (independent) audit and validation. Who is auditing data accuracy?

\section{Is the rationale for, and objectives of, the study clearly described?}


Is the study design appropriate for the research question?

Yes

Are sufficient details of the methods provided to allow replication by others?

Yes

Are the datasets clearly presented in a useable and accessible format?

Yes

Competing Interests: No competing interests were disclosed.

Reviewer Expertise: Colorectal surgery, minimally-invasive surgery

I confirm that I have read this submission and believe that I have an appropriate level of expertise to confirm that it is of an acceptable scientific standard.

Reviewer Report 05 November 2019

https://doi.org/10.5256/f1000research.22769.r55011

(C) 2019 Fingerhut A. This is an open access peer review report distributed under the terms of the Creative Commons Attribution License, which permits unrestricted use, distribution, and reproduction in any medium, provided the original work is properly cited.

\section{Abe Fingerhut}

Section for Surgical Research, Department of Surgery, Medical University of Graz, Graz, Austria

This registry is unique and essential to reseach in Italy.

The Advanced International Mini-Invasive Surgery (AIMS) academy clinical research network has a major role in this multicenter prospective observational cohort study, I agree that standardization and centralization of data collection for neoplastic diseases is essential for patient care. The creation of a register will allow the control of the quality of treatments provided and permit prospective and retrospective studies to be carried out on complete and reliable high quality data.

Is the rationale for, and objectives of, the study clearly described?

Yes

Is the study design appropriate for the research question?

Yes

Are sufficient details of the methods provided to allow replication by others? Yes

Are the datasets clearly presented in a useable and accessible format? Yes 
Competing Interests: No competing interests were disclosed.

Reviewer Expertise: Surgery and clinical research

I confirm that I have read this submission and believe that I have an appropriate level of expertise to confirm that it is of an acceptable scientific standard.

Reviewer Report 17 October 2019

https://doi.org/10.5256/f1000research.22769.r55012

(C) 2019 Cesana G. This is an open access peer review report distributed under the terms of the Creative Commons Attribution License, which permits unrestricted use, distribution, and reproduction in any medium, provided the original work is properly cited.

\section{Giovanni Cesana}

${ }^{1}$ Department of Surgery, S.I.C.OB. (Italian Society of Bariatric Surgery) Referral Center for Bariatric Surgery, San Donato Group, Policlinico San Marco, Zingonia, Italy

2 Policlinico San Marco, Zingonia, Italy

This paper describes the creation of a national registry for non metastatic rectal cancer. The main issue is a high quality standardization of rectal cancer multimodal treatment, staging and follow up.

I think that the core of the project is well explained and clarified. Additional materials are clear and quite user friendly.

The methods are well described and expanded enough.

The need for well designed databases on rectal cancer is clearly expressed by the literature.

I believe that this registry represents a high quality attempt in the direction of a centralized and appropriate treatment for rectal cancer.

Is the rationale for, and objectives of, the study clearly described?

Yes

Is the study design appropriate for the research question?

Yes

Are sufficient details of the methods provided to allow replication by others? Yes

Are the datasets clearly presented in a useable and accessible format? Yes

Competing Interests: No competing interests were disclosed.

Reviewer Expertise: Colorectal surgery 
I confirm that I have read this submission and believe that I have an appropriate level of expertise to confirm that it is of an acceptable scientific standard.

The benefits of publishing with F1000Research:

- Your article is published within days, with no editorial bias

- You can publish traditional articles, null/negative results, case reports, data notes and more

- The peer review process is transparent and collaborative

- Your article is indexed in PubMed after passing peer review

- Dedicated customer support at every stage

For pre-submission enquiries, contact research@f1000.com 